\title{
A study of hypertension in twins
}

\author{
Ronald VanderMolen, M.D.* \\ George Brewer, M.D. \\ M. S. Honeyman, Ph.D. \\ John Morrison, M.D.** \\ S. W. Hoobler, M.D.*** \\ Ann Arbor, Mich., and Hartford, Conn.
}

$\mathrm{P}$ atients with arterial hypertension are frequently found to have a strongly positive family history for this condition. To shed more light on the possible role of genetic influences in this disease, a systematic study of identical and fraternal twins was undertaken. For many years, research interest has been drawn to the possibility that a genetic basis may exist for the common hypertension that appears in middle age without apparent cause. Considerable evidence has accumulated suggesting that there is an inheritance factor which probably represents multiple genetic influences. Familial studies therefore continue to provide practical information of various kinds, and in particular the study of twins helps to shed light on pathogenesis and the question of environmental versus genetic factors.

A number of authors ${ }^{1-7}$ have reported concordant hypertension in identical twins. Only Friedman and Kasanin ${ }^{8}$ have reported discordant hypertension in a single pair of twins with identical blood groups but widely divergent personalities. However, most of these studies of concordance have been influenced adversely by the "ascertainment factor"- that is, that when a physician learns that his hypertensive patient has an identical twin, and finds that the twin's blood pressure also is elevated, he is more likely to report his findings than if the sibling were found normotensive. Consequently, the true concordance rates for hypertension in identical twins is not known.

Another problem in twin studies is that essential hypertension is a disease which expresses itself late in lif $\mathrm{e}^{1,9}$; hence if the twins studied were young and the disease became apparent earlier in one twin than the other, poor concordance between blood pressure levels might be observed at any given time.

In the study reported here, the ascertainment factor was almost negligible because the sample was comprised of twins selected

\footnotetext{
From the Departments of Human Genetics and Internal Medicine, University of Michigan, Ann Arbor, Mich., and the Chronic Disease Control Section. State of Connecticut Department of Health. Hartford, Conn.

This investigation was supported in part by Public Health Research Grant HE 07544 from the National Heart Institute. Received for publication June 13, 1969.

* Completed during tenure of a senior student research fellowship.

**Trainee, United States Public Health Service, Division of Chronic Disease Control.

****Reprint requests to: Dr. Hoobler, Department of Internal Medicine, University Hospital, University of Michigan Medical Center, Ann Arbor, Mich. 48104.
} 
only according to age and geographic location. Blood pressure levels were determined in both members of the pair in every case. The opportunity to carry out such a study was provided through the use of the Connecticut Twin Registry, which contains a record of all multiple births occurring in Connecticut since 1897, and also a file indicating the current address of many of the twins.

\section{Methods}

The first step was to send a letter to likesexed pairs of twins in the vicinity of Hartford over the age of 40 , requesting permission for one of us (R. V.) to visit them in

Table I. Observations in all twin pairs with hypertension*

\begin{tabular}{|c|c|c|c|c|c|}
\hline \multirow{2}{*}{ No. } & \multirow{2}{*}{$\underset{\text { sex }}{\text { Age and }}$} & \multicolumn{2}{|c|}{ Blood pressure on visit } & \multirow{2}{*}{$\begin{array}{l}\text { Marital status, } \\
\text { no. children }\end{array}$} & \multirow{2}{*}{$\begin{array}{l}\text { Weight now and } \\
\text { change since } \\
\text { age } 20\end{array}$} \\
\hline & & No. 1 & No. 2 & & \\
\hline \multicolumn{6}{|c|}{ Monozygotic $\dagger$} \\
\hline $1 \mathrm{H}$ & $51, \mathrm{~F}$ & $164 / 118$ & $168 / 108$ & M, 2 & $118(-16)$ \\
\hline $2 \mathrm{H}$ & & $160 / 114(\mathrm{Rx})$ & $156 / 106(\mathrm{Rx})$ & $\mathrm{M}, 2$ & $118(-17)$ \\
\hline $3 \mathrm{H}$ & $63, \mathrm{~F}$ & $186 / 112$ & $190 / 96$ & $\mathrm{~S}, 0$ & $165(+46)$ \\
\hline 4 & & $222 / 116$ & $182 / 90$ & $\mathrm{~S}, 0$ & $185(+66)$ \\
\hline $5 \mathbf{H}$ & $51, M$ & $190 / 116(\mathrm{Rx})$ & $188 / 102(\mathrm{Rx})$ & $\mathrm{M}, 3$ & $135(+15)$ \\
\hline $6 \mathrm{H}$ & & $192 / 102$ & $200 / 110$ & $\mathrm{M}, 2$ & $190(+25)$ \\
\hline $7 \mathrm{H}$ & $43, \mathrm{M}$ & $164 / 100$ & $178 / 98$ & $\mathrm{M}, 2$ & $168(+38)$ \\
\hline $8 \mathrm{H}$ & & $156 / 100$ & $146 / 96$ & M, 0 & $179(+29)$ \\
\hline $9 \mathrm{H}$ & $43, \mathrm{~F}$ & $138 / 95$ & - & M, 1 & $180(+50)$ \\
\hline $10 \mathrm{H}$ & & $152 / 104$ & 一 & $M, 2$ & $175(+45)$ \\
\hline \multicolumn{6}{|c|}{ Dizygotic-concordant } \\
\hline $11 \mathrm{H}$ & $46, \mathrm{M}$ & $240 / 144$ & $162 / 104$ & M, 2 & $190(+55)$ \\
\hline $12 \mathrm{H}$ & & $194 / 108$ & $174 / 102$ & M, 2 & $174(+39)$ \\
\hline $13 \mathrm{H}$ & $66, F$ & $194 / 106$ & $184 / 100$ & $\mathrm{~W}, 0$ & $180(+50)$ \\
\hline $14 \mathrm{H}$ & & $164 / 94(\mathrm{Rx})$ & $166 / 100(\mathrm{Rx})$ & M, 6 & $155(+55)$ \\
\hline $15 \mathrm{H}$ & $61, \mathrm{M}$ & $154 / 100$ & $154 / 102$ & $S, 0$ & $160(+30)$ \\
\hline $16 \mathrm{H}$ & & $168 / 88(\mathrm{Rx})$ & $158 / 86(\mathrm{Rx})$ & $\mathrm{S}, 0$ & $179(+4)$ \\
\hline \multicolumn{6}{|c|}{ Dizygotic-discordant $\dagger$} \\
\hline $17 \mathrm{H}$ & $40, \mathrm{~F}$ & $144 / 82(\mathrm{Rx})$ & $164 / 100(\mathrm{Rx})$ & $\mathrm{M}, 0$ & $140(-10)$ \\
\hline 18 & & $132 / 96$ & $134 / 80$ & $\mathrm{~W}, 1$ & $190(+40)$ \\
\hline $19 \mathrm{H}$ & $56, \mathrm{~F}$ & $188 / 110(\mathrm{Rx})$ & $174 / 98(\mathrm{Rx}) \ddagger$ & $\mathrm{M}, 1$ & $120(+20)$ \\
\hline 20 & & $136 / 86$ & $124 / 72 t$ & $\mathrm{M}, 0$ & $128(+23)$ \\
\hline $21 \mathrm{H}$ & $56, \mathrm{~F}$ & $200 / 104$ & $190 / 104 \ddagger$ & $S, 0$ & $95(-20)$ \\
\hline 22 & & $130 / 90$ & $106 / 78 \ddagger$ & $M, 1$ & $127(+12)$ \\
\hline $23 \mathrm{H}$ & $47, \mathrm{~F}$ & $162 / 100$ & $156 / 104$ & $M, 3$ & $198(+79)$ \\
\hline 24 & & $114 / 80$ & - & $\mathrm{M}, 0$ & $97(-3)$ \\
\hline $25 \mathrm{H}$ & $59, \mathrm{~F}$ & $160 / 104$ & $132 / 96 \ddagger$ & $M, 1$ & $145(+25)$ \\
\hline 26 & & $134 / 80$ & $118 / 76 \ddagger$ & $\mathrm{M}, 2$ & $130(+5)$ \\
\hline $27 \mathrm{H}$ & $50, \mathrm{~F}$ & $154 / 98$ & $126 / 80(\mathrm{Rx})$ & $M, 1$ & $145(+25)$ \\
\hline 28 & & $110 / 72$ & - & $\mathrm{D}, 2$ & \\
\hline $29 \mathrm{H}$ & $41, \mathrm{~F}$ & $158 / 98$ & $144 / 96$ & $\mathrm{M}, 3$ & $122(+26)$ \\
\hline 30 & & $114 / 70$ & $102 / 68$ & $\mathrm{M}, 2$ & $126(+8)$ \\
\hline $31 \mathrm{H}$ & $52, \mathrm{M}$ & $184 / 96$ & - & $\mathrm{M}, 2$ & $185(+55)$ \\
\hline 32 & & $150 / 86$ & - & M, 1 & $150(+25)$ \\
\hline $33 \mathrm{H}$ & $56, \mathrm{~F}$ & $164 / 96(\mathrm{Rx})$ & $130 / 74(\mathrm{Rx})$ & $S, 0$ & $146(+26)$ \\
\hline 34 & & $150 / 80$ & $142 / 80$ & S, 0 & $152(+34)$ \\
\hline
\end{tabular}

*Defined as diastolic blood pressure above $94 \mathrm{~mm}$. Hg on first visit. "H" (which appears after the subject's no.) means, by arbitrary definition. that the individual was considered hypertensive (blood pressure in excess of $94 \mathrm{~mm}$. $\mathrm{Hg}$ on second visit) or under treatment for hypertension.

$\nmid Z y$ gosity based on appearance, concordance in blood groups, and opinion of twins themselves.

\$Second blood pressure taken from records at State Health Department examination.

$M$, Married; $S$, single; $\mathfrak{D}$, divorced; $W$, widowed; $(R x)$, under antlhypertenslve treatment. 
their homes to obtain information for a questionnaire. The purpose of the study was not mentioned in the lettcr. Favorable replies came from 86 pairs of twins, representing 85 per cent of the number of twin sets contacted by mail.

At the home visit, after completing a brief questionnaire, the examiner determined the sitting blood pressure three times on the right arm, then on the left, then again three times on the right. The last three readings (using fifth phase as diastolic end point) were averaged and recorded as the blood pressure of the propositus. To prevent bias, the examiner purposely avoided having knowledge of the blood pressure of the sibling of the twin he was examining. If the diastolic blood pressure was above $94 \mathrm{~mm}$. $\mathrm{Hg}$, a second visit was requested for both the twin and his sibling. The twin was considered to be hypertensive if the blood pressure remained above 94 or if he was known to be under treatment for hypertension. In a few instances where readings had been taken previously in the course of a health department examination, these were used as second readings. On the second visit, blood was obtained for confirmation of zygosity.

\section{Results}

Among the 86 twin pairs examined, hypertension was found in 17 sets of twins, 5 of them monozygotic. As shown in Table I, 24 individuals in the 17 twin sets showed hypertension according to the criteria for this study. In 3 cases hypertension was noted at the first visit but a repeat visit could not be made.

There were 37 pairs of monozygotic twins over age 40 in the study; hypertension was found in 9 individuals or 12.2 per cent of this group. In one instance (twin no. 4), the diastolic blood pressure fell below 95 $\mathrm{mm}$. $\mathrm{Hg}$ on the second visit, but the systolic pressure remained within the hypertensive range. This was the oldest pair of identical twins and the only one of 5 identical sets in which hypertension might be considered discordant. The magnitude of diastolic blood pressure elevation was comparable in each twin set, being within a range of 10 $\mathrm{mm} . \mathrm{Hg}$ in all of the identical twins.

Although the sample size is limited, a calculation by the chi square method with
Yates correction for continuity shows an increased concordance of hypertension in monozygotic twins at about the 6 per cent level of confidence.

There were 49 pairs of dizygotic twins included in the study; 15 individuals or 15.3 per cent of the sample were considered hypertensive. In 3 of 12 dizygotic twin sets each member was found to be hypertensive. In 9 other pairs only one member was hypertensive.

A variety of additional observations are listed in Table I. Certain variables commonly thought to be associated with hypertension, such as weight changes, sex, marital status, and number of pregnancies, did not seem to affect concordance rates in the identical twins. They had lived apart for a median period of 16 years.

In two pairs of identical twins (nos. 1 and 2,5 and 6), the age at onset of hypertension differed considerably, as indicated by a study of the records and by correspondence with the family physicians involved. In the first pair, twin no. 2 exhibited hypertension $(140 / 100)$ at the age of 35 , whereas her partner's blood pressure presumably remained normal until at least age 49 , when she reported that she had been permitted to donate blood. Yet two years later both twins showed hypertension of about an equal magnitude. Similarly, the blood pressure in twin no. 5 was reported by his physician to have been $124 / 80$ at age 32 , while his sibling had a blood pressure of $160 / 100$ at about the same time; at age 51 both showed a comparable blood pressure level.

\section{Discussion}

The remarkably high degree of concordance for hypertension between pairs of identical twins over age 40 selected at random from the general population leaves the impression that this condition is under a very strong genetic influence. It is unfortunate that the material is too limited to yield a value of high statistical significance $(p=0.06)$. Twenty-five per cent of dizygotic twin pairs showed concordance rates for hypertension. This again suggests that a genetic influence plays an important part in this disease, since the frequency of this condition in the total population studied was only 15 per cent. Again, the sample 
is too small to establish a statistically significant difference.

The prevalence of elevated blood pressure (12.2 per cent) in the identical twin sample resembles that in the general population of a similar age. Thus, unless the expression of this condition is different in twins than in the population at large, it may be concluded that most cases of essential hypertension which appear in late middle-age are determined by heredity.

Physicians' records in the case of two monozygotic twin pairs support the view that among genetically predisposed individuals the condition may develop at different ages, perhaps dependent on environmental factors; but that the overall result of inherited influences will nevertheless become manifest in the fifth or sixth decade of life with remarkable uniformity. This view supports the important observations of Platt ${ }^{1}$ cited previously. If a predisposition to hypertension could be identified early in life, surveillance and appropriate early treatment would be of great practical importance.

\section{Summary}

A study of the blood pressure of 86 pairs of likc-scxed twins over age 40 selected at random was performed. Twelve per cent were found to have a diastolic blood pressure in excess of $94 \mathrm{~mm}$. $\mathrm{Hg}$. In 4 out of 5 identical twin sets both members were found to have hypertension of about equal magnitude. In the fifth set, the predetermined definition of diastolic hypertension was not met in one member of the pair, although the systolic blood pressure was clearly elevated. In two identical twin sets, where information concerning previous blood pressure could be obtained, the age of onset of the hypertension differed. Among the 49 dizygotic twin sets, diastolic hypertension was found in 15 per cent of the individuals. In 3 of 12 of these pairs, it was present in both members.

Since the prevalence of hypertension after age 40 in the identical twin sample resembles that in the population at large, it is concluded that the ultimate development of this condition is heavily dependent on genetic influences.

The authors express their indebtedness to the late Dr. A. C. Corcoran, who contributed much to the planning of the project.

\section{REFERENCES}

1. Platt, R.: Heredity in hypertension, Lancet 1:899, 1963.

2. Hines, E. A., McIlhaney, M. L., and Gage, R. P.: A study of twins with normal blood pressures and with hypertension, Trans. A. Am. Physicians 70:282, 1957.

3. Hames, C. G., McDonough, J. R., and Elliott, J. L.: Hypertension in identical twins, Lancet 2:585, 1964 .

4. Heizer, W. D., and Lewison, E. F.: Concordant disease in identical twins, J. A. M. A. 188:217, 1964.

5. Frohlich, K.: Jugenliche $Z$ willinge mit arteriellen Hochdruck, Med. Klinik 33:1196, 1937.

6. Weitz, W.: Studien on eineigen Zwillingen, Ztschr. fur Klin. Med. 101:115, 1925.

7. Klemola, E.: Essentielle Hypertonie bei 23 jahrigen eineiigen $Z$ willingen, $Z$ tschr. Konst. Lehre 22:69, 1938.

8. Friedman, M., and Kasanin, J. S.: Hypertension in only one of identical twins, Arch. Int. Med. $72: 767,1943$.

9. Perera, G. A.: Hypertensive vascular disease. Description and natural history, J. Chron. Dis. $1: 33,1955$. 